\title{
Sintesis dan Analisis Struktur Material Aktif Katoda $\mathrm{LiFe}_{0}{ }_{7} \mathrm{Mn}_{0,}{ }_{2} \mathrm{Ni}_{0,1} \mathrm{PO}_{4}$
}

\author{
Betty Haifa Sarwono ${ }^{1, \dagger}$, Siti Ahmiatri ${ }^{1}$, Bambang Prihandoko ${ }^{2}$ \\ ${ }^{1}$ Program Studi Fisika, Fakultas Sains dan Teknologi, Universitas Islam Negeri Syarif Hidayatullah \\ Jakarta \\ ${ }^{2}$ Pusat Peneitian Fisika LIPI, Kawasan Puspiptek, Serpong 15314, Tangerang selatan \\ †corresponding author: bettyhaifa@gmail.com
}

\begin{abstract}
Abstrak. Sebuah sintesis material katoda $\mathrm{LiFe}_{0,7} \mathrm{Mn}_{0,}{ }_{2} \mathrm{Ni}_{0,1} \mathrm{PO}_{4}$ dengan metode solid-state telah selesai dilakukan. Bahan dasar yang digunakan adalah $\mathrm{LiOH} . \mathrm{H} 2 \mathrm{O}, \alpha-\mathrm{Fe}_{2} \mathrm{O}_{3}, \mathrm{MnO}_{2}, \mathrm{Ni}$ dan $\mathrm{H}_{3} \mathrm{PO}_{4}$. Bahan yang digunakan ada yang berasal dari bahan baku lokal yaitu $\alpha-\mathrm{Fe}_{2} \mathrm{O}_{3}$ dan $\mathrm{MnO}_{2}$ dan sisanya menggunakan bahan import dari china. Pada penelitian ini digunakan variasi waktu sintering yaitu 4 jam, 6 jam, 8 jam dan total 10 jam dengan temperatur $800^{\circ} \mathrm{C}$. Karakterisasi dilakukan dengan menggunakan pengujian Difraktometer Sinar-X (XRD). Analisis data XRD dilakukan dengan menggunakan perangkat lunak PDXL Rigaku. Hasil analisis menunjukkan bahwa sintering pada temperatur $800^{\circ} \mathrm{C}$ selama total 10 jam menghasilkan fasa $\mathrm{LiFe}_{0,7} \mathrm{Mn}_{0,2} \mathrm{Ni}_{0}$, ${ }_{1} \mathrm{PO}_{4}$ yang satu fasa. Dan co-doping $\mathrm{Mn}$ dan Ni berhasil didoping pada $\mathrm{LiFePO}_{4}$.
\end{abstract}

Kata Kunci: sintering, $\mathrm{LiFe}_{0,7} \mathrm{Mn}_{0,}{ }_{2} \mathrm{Ni}_{0,1} \mathrm{PO}_{4}$, solid-state

Abstract. Synthesis Cathode material, $\mathrm{LiFe}_{0,7} \mathrm{Mn}_{0,2} \mathrm{Ni}_{0,1} \mathrm{PO}_{4}$, has been synthesized by the solidstate method. Basic materials that used in this research are $\mathrm{LiOH} . \mathrm{H}_{2} \mathrm{O}, \alpha-\mathrm{Fe}_{2} \mathrm{O}_{3}, \mathrm{MnO}_{2}, \mathrm{Ni}$, and $\mathrm{H}_{3} \mathrm{PO}_{4}$. Several basic materials that used in this research obtained from the local raw material such as $\alpha-\mathrm{Fe}_{2} \mathrm{O}_{3}$ and $\mathrm{MnO}_{2}$, and the remaining materials obtained by importing from China. Sintering time in this research are varied from 4 hours, 6 hours, 8 hours, and 10 hours, and all varied time are treated at $800^{\circ} \mathrm{C}$. The characterization that used in this research is $\mathrm{X}$-Ray Diffractometer (XRD). XRD data are analyzed using PDXL Rigaku software. The results of this research show that sintering at $800^{\circ} \mathrm{C}$ during total time 10 hours yields $\mathrm{LiFe}_{0,7} \mathrm{Mn}_{0,2} \mathrm{Ni}_{0,1} \mathrm{PO}_{4}$ in one phase. Co-doping $\mathrm{Mn}$ and $\mathrm{Ni}$ had been successfully doped in $\mathrm{LiFePO}_{4}$.

Keywords: sintering, $\mathrm{LiFe}_{0,7} \mathrm{Mn}_{0,2} \mathrm{Ni}_{0,1} \mathrm{PO}_{4}$, solid-state

\section{PENDAHULUAN}

Penggunaan peralatan elektronik seperti handphone dan laptop semakin meningkat. Hal ini menyebabkan perlunya peralatan penyimpan energi listrik yang efisien, bahan baku mudah diperoleh, ekonomis, ramah lingkungan dan berkapasitas tinggi. Salah satu jenis baterai yang memiliki beda potensial tinggi, densitas energi yang tinggi dan stabilitas cycling yang baik yaitu baterai ion lithium. Baterai ion lithium sudah banyak digunakan sebagai sumber energi untuk peralatan elektronik portable bahkan pada mobil listrik. Baterai lithium terdiri dari tiga komponen utama yaitu elektrolit, anoda dan katoda.

Beberapa material katoda pada baterai lithium yang telah disintesis yaitu $\mathrm{LiFePO}_{4}$, $\mathrm{LiCoO}_{2}$ dan $\mathrm{LiMnPO}_{4}$. Dari ketiganya $\mathrm{LiCoO}_{2}$ memiliki kapasitas spesifik tertinggi dan koduktivitas listrik yang cukup tinggi yaitu $10^{-3} \mathrm{~S} / \mathrm{cm}$ [1], namun material ini harganya mahal dan tidak ramah lingkungan karena mengandung logam berat. Sedangkan pada material $\mathrm{LiMnPO}_{4}$ mudah dibuat, ramah lingkungan dan harga terjangkau namun memiliki kekurangan yaitu performa yang buruk [2].

$\mathrm{LiFePO}_{4}$ (Litihium iron phosphate) diteliti sebagai material katoda baterai lithium-ion dengan harga yang murah, tidak beracun, ramah lingkungan, biaya fabrikasi rendah, kestabilan termal, aman dan terbentuk dari unsur - unsur yang banyak dialam, dan memiliki densitas energi 
yang tinggi. Akan tetapi $\mathrm{LiFePO}_{4}$ mempunyai kekurangan yaitu specific capacity yang lebih rendah dibandingkan dengan $\mathrm{LiMnPO}_{4}$ dan $\mathrm{LiNiPO}_{4}$. Untuk meningkatkan kapasitas spesifik dengan cara mendoping bahan-bahan lain seperti Mn dan $\mathrm{Ni}$.

$\mathrm{LiFePO}_{4}$ (Lithium iron phosphate) merupakan material katoda baru yang digunakan pada baterai ion lithium. $\mathrm{LiFePO}_{4}$ sebagai material pembentuk katoda menunjukkan bahwa keduanya memenuhi kriteria sebagai material katoda pada baterai ion lithium dimana keduanya memiliki reversibility yang baik untuk pasangan redoks $\mathrm{Fe}^{3+} / \mathrm{Fe}^{2+}$ [3]. Dalam keadaan oksidasi, ion besi pada $\mathrm{LiFePO}_{4}$ memiliki bilangan oksidasi 2+. Berbagai metode telah dikembangkan untuk membuat material katoda $\mathrm{LiFePO}_{4}$ yaitu metode solid-state, sol-gel, dan microwave heating [4].

Dari berbagai metode masing-masing memiliki keunggulan dan kelemahan. Dan metode yang paling mudah dilakukan karena persiapan alat sederhana, variabel kontrol mudah adalah reaksi solid-state. Dimana metode ini merupakan metode pencampuran dua material atau lebih.

Penelitian sebelumnya di Pusat Penelitian Fisika LIPI telah berhasil membuat $\mathrm{LiFePO}_{4}$ sebagai katoda baterai lithium ion tetapi masih menggunakan bahan-bahan yang terbuat dari China. Dalam penelitian akan dipakai bahan-bahan seperti $\mathrm{MnO}_{2}$ dan $\alpha-\mathrm{Fe}_{2} \mathrm{O}_{3}$ yang dibuat dari bahan lokal yang didapatkan dari P2 Metalurgi \& Material LIPI. Pada penelitian ini bertujuan untuk membentuk material $\mathrm{LiFe}_{0},{ }_{7} \mathrm{Mn}_{0},{ }_{2} \mathrm{Ni}_{0},{ }_{1} \mathrm{PO}_{4}$ melalui mekanisme solid-state, dan mengetahui fasa yang terbentuk dari pembentukkan material $\mathrm{LiFe}{ }_{0,7} \mathrm{Mn}_{0,2} \mathrm{Ni}_{0,1} \mathrm{PO}_{4}$.

\section{METODE PENELITIAN}

Langkah awal penelitian menyiapkan bahan-bahan dasar mengikuti perbandingan massa dan molar masing-masing bahan sesuai dengan stokiometri. Bahan bahan yang digunakan yaitu LiOH. $\mathrm{H}_{2} \mathrm{O}, \alpha-\mathrm{Fe}_{2} \mathrm{O}_{3}, \mathrm{MnO}_{2}, \mathrm{Ni}, \mathrm{H}_{3} \mathrm{PO}_{4}$. Bahan bahan semua ditimbang kemudian dicampur dengan menggunakan mortar dan gelas beaker, setelah semua bahan-bahan tercampur merata kemudian dikeringkan kedalam oven sampai mengeras. Setelah bahan mengeras kemudian digerus dan diayak 200 mesh. Selanjutnya dikalsinasi pada temperatur $700^{\circ} \mathrm{C}$ selama 2 jam untuk menghilangkan zat volatil. Setelah dikalsinasi kemudian digerus lagi, yang selanjutnya memasuki proses sintering pada temperatur $800^{\circ} \mathrm{C}$ dengan variasi waktu 4 jam, 6 jam, 8 jam dan hasil sintering 8 jam ditambahkan dengan soft carbon yaitu tepung tapioka (sintering 10 jam). Soft carbon digunakan untuk penstabil fasa yang berbentuk amorf. Selanjutnya serbuk $\mathrm{LiFe}_{0}$, ${ }_{7} \mathrm{Mn}_{0,2} \mathrm{Ni}_{0,1} \mathrm{PO}_{4}$ dikarakterisasi menggunakan $X$-Ray Diffraction (XRD).

\section{HASIL DAN PEMBAHASAN}

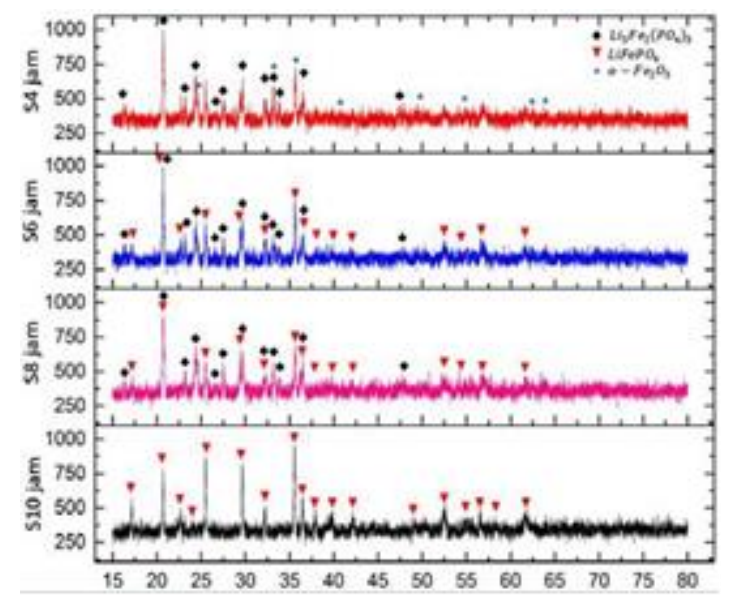

GAMBAR 1. Pola Difraksi pada $\mathrm{LiFe}_{0,} \mathrm{Mn}_{0,2} \mathrm{Ni}_{0,1} \mathrm{PO}_{4}$ sintering 4 jam 6 jam 8 jam dan 10 jam

Analisis pola difraksi pada $\mathrm{LiFe}_{0,7} \mathrm{Mn}_{0,2} \mathrm{Ni}_{0,1} \mathrm{PO}_{4}$ Secara kualitatif , pola difraksi yang tertera pada Gambar 1 terlihat bahwa posisi puncak-puncak dari serbuk yang disintering pada temperature $800^{\circ} \mathrm{C}$ selama 4 jam, 6 jam, 8 jam dan 10 jam berada pada posisi yang sama dengan 
puncak $\mathrm{LiFePO}{ }_{4}$ dan $\mathrm{Li}_{3} \mathrm{Fe}_{2}\left(\mathrm{PO}_{4}\right)_{3}$. Puncak-puncak ini mengacu pada pola difraksi nomor PDF: 04-015-6070 untuk $\mathrm{LiFePO}_{4}$. Nomor PDF: 04-001-3207 untuk $\mathrm{Li}_{3} \mathrm{Fe}_{2}\left(\mathrm{PO}_{4}\right)_{3}$ atau fasa NASICON dan $\mathrm{Fe}_{2} \mathrm{O}_{3}$ dengan nomor PDF: 01-089-0596. Pada waktu sintering 4 jam terdeteksi fasa $\mathrm{Li}_{3} \mathrm{Fe}_{2}\left(\mathrm{PO}_{4}\right)_{3}$ dan fasa $\alpha-\mathrm{Fe}_{2} \mathrm{O}_{3}$. Terdeteksinya fasa $\alpha-\mathrm{Fe}_{2} \mathrm{O}_{3}$ yang merupakan bahan baku, berarti waktu sintering yang diberikan masih belum cukup untuk membakar semua bahanbahan. Pada waktu sintering 6 terdeteksi fasa $\mathrm{Li}_{3} \mathrm{Fe}_{2}\left(\mathrm{PO}_{4}\right)_{3}$ dan fasa $\mathrm{LiFePO}_{4}$, pada waktu sintering 6 jam sudah terbentuk fasa $\mathrm{LiFePO}_{4}$. Waktu sintering 8 jam terdeteksi fasa $\mathrm{LiFePO}_{4}$ dan $\mathrm{Li}_{3} \mathrm{Fe}_{2}\left(\mathrm{PO}_{4}\right)_{3}$. Pada waktu sintering 10 jam dihasilkan dari pencampuran hasil sintering 8 jam dengan tepung tapioka sebagai penstabil fasa. Hasil waktu sintering 10 jam terdeteksi fasa $\mathrm{LiFePO}_{4}$ yang merupakan single phase.

TABEL 1. Parameter kisi dengan variasi waktu sintering

\begin{tabular}{cccccc}
\hline & Fasa & A & B & C & Chi', Rwp \\
\hline \multirow{2}{*}{ Sintering 4 Jam } & $\mathrm{Li}_{3} \mathrm{Fe}_{2}(\mathrm{PO} 4)_{3}$ & $8.551(5)$ & $12(6)$ & $8.585(4)$ & \multirow{2}{*}{$1.26,9.94$} \\
& $\mathrm{Fe}_{2} \mathrm{O}_{3}$ & $5.0288(15)$ & $5.0288(15)$ & $13.726(5)$ & \\
\multirow{2}{*}{ Sintering 6 Jam } & $\mathrm{LiFe}\left(\mathrm{PO}_{4}\right)$ & $10.273(3)$ & $6.0035(19)$ & $4.713(16)$ & $1.07,9.4$ \\
& $\mathrm{Li}_{3} \mathrm{Fe}_{2}\left(\mathrm{PO}_{4}\right)_{3}$ & $8.579(4)$ & $12.049(6)$ & $8.610(4)$ & \\
\multirow{2}{*}{ Sintering 8 Jam } & $\mathrm{LiFe}\left(\mathrm{PO}_{4}\right)$ & $10.298(5)$ & $6.014(3)$ & $4.729(90)$ & $1.13,9.3$ \\
& $\mathrm{Li}_{3} \mathrm{Fe}_{2}\left(\mathrm{PO}_{4}\right)_{3}$ & $8.590(4)$ & $12.050(6)$ & $8.623(4)$ & $1.071,9.33$ \\
\hline
\end{tabular}

Dengan bertambahnya waktu sintering akan menyebabkan kristalinitas fasa bertambah. Dalam pola difraksi, fenomena ini dapat dilihat pada intesitas yang meningkat dan puncak puncaknya menyempit. Hal ini dikarenakan keteraturan bidang kristal meningkat sehingga bidang-bidang kristal yang terdeteksi oleh peralatan XRD semakin bertambah dan menyebabkan intesitas yang dihasilkan semakin tinggi.

Pola XRD dari $\mathrm{LiFe}_{0,} \mathrm{Mn}_{0,} \mathrm{Ni}_{0,}{ }_{1} \mathrm{PO}_{4}$ sintering pada temperatur $800^{\circ} \mathrm{C}$ dengan variasi waktu 4 jam, 6 jam, 8 jam dan 10 jam dianalisis dengan menggunakan metode rietveld. Nilai Rwp dan chi-square yang diperoleh sudah baik karena nilai Rwp sudah dibawah $10 \%$ dan nilai chi-square dibawah 1.3 yang ditunjukkan pada Tabel 1.

Kemudian, doping $\mathrm{Mn}$ dan $\mathrm{Ni}$ pada $\mathrm{LiFePO}_{4}$ tidak mengubah struktur kristal dari sampel sintering $800^{\circ} \mathrm{C}$ dengan waktu 4 jam, 6 jam, 8 jam, dan 10 jam. Doping Mn dan Ni menempati situs Fe sehingga tidak merubah struktur pada kristal $\mathrm{LiFePO}_{4}$ yang terlihat pada Tabel 2.

TABEL 2. Parameter Struktur sintering $800^{\circ} \mathrm{C} / 10$ jam

\begin{tabular}{ccccc}
\hline Element & $\mathbf{X}$ & $\mathbf{Y}$ & $\mathbf{Z}$ & Occupancy \\
\hline $\mathrm{Li}$ & 0.000000 & 0.000000 & 0.00000 & 1.000 \\
$\mathrm{Fe}$ & 0.282220 & 0.250000 & 0.97472 & 0.700 \\
$\mathrm{P}$ & 0.094860 & 0.250000 & 0.41820 & 1.000 \\
$\mathrm{O}$ & 0.096780 & 0.250000 & 0.74279 & 1.000 \\
$\mathrm{O}$ & 0.457100 & 0.250000 & 0.20602 & 1.000 \\
$\mathrm{O}$ & 0.165580 & 0.046460 & 0.28478 & 1.000 \\
$\mathrm{Mn}$ & 0.282220 & 0.250000 & 0.97472 & 0.200 \\
$\mathrm{Ni}$ & 0.282220 & 0.250000 & 0.97472 & 0.100 \\
\hline
\end{tabular}

Secara kuantitatif, pencocokan data posisi-posisi puncak difraksi terukur dengan database fasa-fasa dalam bentuk PDF dilakukan dengan menggunakan software PDXL Rikagu.

TABEL 3. Persentase fasa

\begin{tabular}{cccc}
\hline \multirow{2}{*}{ Waktu sintering } & \multicolumn{3}{c}{ Komposisi fasa (\%) } \\
\cline { 2 - 4 } & $\mathrm{LiFePO}_{4}$ & $\mathbf{L i}_{3} \mathrm{Fe}_{2}\left(\mathrm{PO}_{4}\right)_{3}$ & $\boldsymbol{\alpha}-\mathrm{Fe}_{2} \mathbf{O}_{3}$ \\
\hline 4 jam & - & 84 & 16
\end{tabular}




$\begin{array}{cccc}6 \text { jam } & 54.7 & 45.3 & - \\ 8 \text { jam } & 39.2 & 60.8 & - \\ 10 \text { jam } & 100 & - & -\end{array}$

Berdasarkan pengamatan secara kuantitatif pada waktu sintering 4 jam fasa $\mathrm{Li}_{3} \mathrm{Fe}_{2}\left(\mathrm{PO}_{4}\right)_{3}$ memiliki persentasi fasa 84 dan adanya fasa $\alpha-\mathrm{Fe}_{2} \mathrm{O}_{3}$ persentasi fasanya yaitu 16. Pada waktu sintering 6 jam terjadi transformasi fasa dari sebagian $\mathrm{Li}_{3} \mathrm{Fe}_{2}\left(\mathrm{PO}_{4}\right)_{3}$ menjadi $\mathrm{LiFePO}_{4}$. Pada waktu sintering 8 jam transformasi fasa dari fasa Nasicon menjadi Fasa $\mathrm{LiFePO}_{4}$. Sedangkan pada waktu sintering $10 \mathrm{jam}$, fasa $\mathrm{LiFePO}_{4}$ memperoleh persentasi $100 \%$. Berdasarkan penjelasan, dapat diketahui bahwa fasa $\mathrm{Li}_{3} \mathrm{Fe}_{2}\left(\mathrm{PO}_{4}\right)_{3}$ merupakan fasa metastabil dimana memiliki kecenderungan bertransformasi fasa.

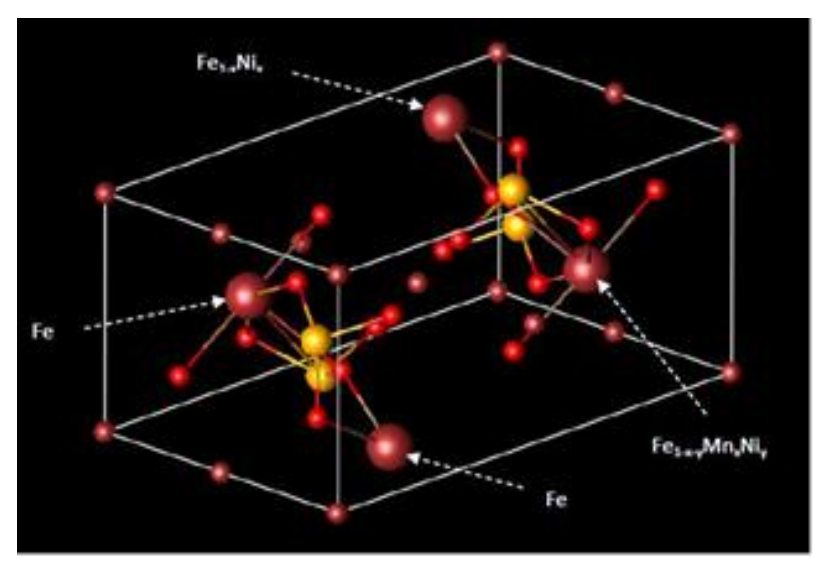

GAMBAR 2. Struktur $\mathrm{LiFePO}_{4}$ doping Mn dan Ini

Sintering pada temperatur $800^{\circ} \mathrm{C}$ selama 8 jam mempunyai fasa yang sama dengan sintering pada temperatur $800^{\circ} \mathrm{C}$ selama 6 jam sehingga strukturnya juga sama, $\mathrm{LiFePO}_{4}$ dan $\mathrm{Li}_{3} \mathrm{Fe}_{2}\left(\mathrm{PO}_{4}\right)_{3}$ berstruktur orthorhombic. Namun walaupun $\mathrm{Li}_{3} \mathrm{Fe}_{2}\left(\mathrm{PO}_{4}\right)_{3}$ mempunyai struktur orthorhombic tetapi bentuknya seperti kubus. Dalam $\mathrm{LiFePO}_{4}$, struktur yang stabil adalah orthorhombic. Pada sintering temperatur $800^{\circ} \mathrm{C}$ selama 10 jam terbentuk fasa $\mathrm{LiFePO}_{4}$ yaitu orthorhombic yang strukturnya dapat dilihat pada Gambar 2. Proses sintering pada temperatur $800^{\circ} \mathrm{C}$ selama 10 jam ini sudah berhasil menghasilkan fasa $\mathrm{LiFePO}_{4}$ yang berstruktur orthorhombic yang berbentuk memanjang.

\section{KESIMPULAN} berikut:

Setelah melakukan sintesis dan uji $\mathrm{LiFe}_{0,7} \mathrm{Mn}_{0,2} \mathrm{Ni}_{0,1} \mathrm{PO}_{4}$, diperoleh kesimpulan sebagai

1. Berdasarkan penelitian yang telah berhasil disintesis $\mathrm{LiFe}_{0,7} \mathrm{Mn}_{0,2} \mathrm{Ni}_{0,1} \mathrm{PO}_{4}$ menggunakan bahan baku lokal $\alpha-\mathrm{Fe}_{2} \mathrm{O}_{3}$ dan $\mathrm{MnO}_{2}$ denga reaksi solid-state.

2. $\mathrm{LiFe}_{0,}{ }_{7} \mathrm{Mn}_{0,}{ }_{2} \mathrm{Ni}_{0,1} \mathrm{PO}_{4}$ sintering pada temperatur $800^{\circ} \mathrm{C}$ selama total 10 jam menghasilkan fasa $\mathrm{LiFePO}_{4}$.

3. $\mathrm{LiFePO}_{4}$ telah berhasil didoping oleh $\mathrm{Mn}$ dan $\mathrm{Ni}$ pada sintering pada temperatur $800^{\circ} \mathrm{C}$ selama10 jam.

\section{REFERENSI}

[1] E.I. Santiago, "Structural and electrochemical properties of $\mathrm{LiCoO}_{2}$ prepared by combustion synthesis." Solid state ionic, no158 (2003), pp. 91-102

[2] Bakenov, Zhumabay. Taniguchi, Izumi. $\mathrm{LiMnPO}_{4}$ olivine as a cathode for Lithium Batterius. The open materials science journal no 5 (2011), pp. 222-227

[3] Shu, Hongbo.et al."Improved Electrochemical performance of $\mathrm{LiFePO}_{4} / \mathrm{C}$ cathode via $\mathrm{Ni}$ and $\mathrm{Mn}$ co-doping for lithium-ion batteries. journal of power sources no. 237 (2013), pp. 149-155 
[4] T. Joko, "Rekayasa Bahan $\mathrm{Li}_{\mathrm{x}} \mathrm{TiMn}_{\mathrm{y}} \mathrm{Fe}_{\mathrm{z}}\left(\mathrm{PO}_{4}\right)_{3}$ Sebagai Katoda Solid Polymer Battery (SBB) Lithium.", Thesis S2 Fakultas Teknik Universitas Indonesia, 2011.

[5] Borong Wu, Yonghuan Ren and Ning Li. 2011. "LiFePO4 Cathode Material”.Electric Vehicles $\hat{a} €$ “" The Benefits and Barriers. Dr. Seref Soylu (Ed.).

[6] Ismunandar, Padatan oksida logam : struktur, sintesis, dan sifat-sifatnya (ITB, Bandung, 2006) 